\title{
O fim da tragédia
}

Maria Orquídea Leite de Faria BORGES ${ }^{1}$

Escola Superior de Educação de Coimbra

Falando da tragédia clássica e do seu desenlace funesto, como era de tradição, observamos uma mudança, por volta de 1640, que se traduz numa bifurcação quanto ao desenvolvimento da ação e à questão levantada e exibida em cena. Daqui por diante, duas vias se apresentam à dramaturgia clássica, como nos explica Georges Forestier:

Se quisermos fazer o ponto da situação da tragédia por volta de 1640, quando Corneille, depois do Cid, lança a sua série de tragédias romanas, podemos dizer que a tragédia deixou de ser o relato de um ilustre infortúnio para se converter na encenação de uma atividade heróica face a um conflito político-amoroso, sob a ameaça de um perigo de morte: daqui em diante, o desfecho funesto deixou de ser uma necessidade. Mesmo se depois disso, com Racine, a atividade heróica cede lugar ao arrebatamento da paixão, este dramaturgo não conceberá nunca a tragédia como uma lamentação, mas antes como uma ação que vai avançando ao ritmo das confrontações e dos golpes de teatro. Em última análise, e por muito opostos que possam ser noutros aspectos, Corneille e Racine (mas também Tristan e Rotrou) fundam a sua dramaturgia numa concepção do trágico que não é já a do esmagamento do homem, mas sim a de conflitos interiores insanáveis de que os heróis só por uma superação nobre (Corneille) ou pela morte (Racine) se poderão libertar." (FORESTIER, 1991, p. 838)

A partir daqui delineiam-se um novo conceito e uma nova atitude do homem. O desenlace funesto, obrigatório na tragédia, está agora ultrapassado, o que significa que a esperança regressa ao homem que adquire uma confiança nova em si mesmo e, nessa medida, uma nova dimensão.

Este ponto de viragem não constitui uma novidade, pois que, já na Antiguidade Clássica, Eurípides se permitira dar um novo fôlego à tragédia, tornando-a mais contemporânea e mais realista. Esta preocupação de clareza é visível nos prólogos, que não passam de explicações dirigidas ao público e que nos trazem à mente os Entretiens de Diderot.

As personagens ganham importância, tanto individualmente como pelas relações que estabelecem entre si, ao mesmo tempo que o coro vê o seu papel e o seu relevo diminuírem

\footnotetext{
1 Professora da Escola Superior de Educação de Coimbra, Portugal, desenvolve uma investigação de doutoramento em torno do século XVIII francês e de Marie-Joseph Chénier (tendo descoberto vários manuscritos inéditos deste dramaturgo do final do Século das Luzes). Apresentou comunicações em Portugal (Universidades do Minho, Coimbra e Porto), na Itália (Caserta), em Espanha (Ciudad Real, Gran Canaria e Santiago de Compostela), em França (Poitiers, Paris, Grenoble, Montpellier), no Brasil (Campo Largo), em Cuba (Havana), em Inglaterra (Oxford), e na Irlanda (Galway) sobre o ensino das línguas estrangeiras, a literatura e a história do teatro. E-mail: orquídea@esec.pt.
} 
em nome do realismo - do natural, diria Diderot. O pluralismo das vozes em cena torna a voz do coro dispensável porque supérflua.

A partir da sua confrontação em cena, as personagens devem justificar-se, revelar os seus sentimentos e emoções e defender, por conseguinte, os seus diferentes pontos de vista. Esta necessidade coloca em paralelo o teatro (o gênero trágico) e o tribunal, através do debate oratório sustentado por uma retórica de que os sofistas terão sido os principais obreiros $^{2}$.

O Século das Luzes vai explorar esta via tanto no domínio filosófico como no literário e dramático que se assume como a voz do primeiro. Identificando-se com as Luzes que Miguel Baptista Pereira traduz como "a situação do homem no mundo em luta com o seu destino" (PEREIRA, 1982, p. 443), este século empunha o estandarte do homem ativo, lúcido e responsável pelo seu próprio destino.

Grandes conhecedores e muito próximos da Antiguidade Clássica, uma vez que, à imagem de Sócrates, se atribuem a si mesmos o papel de guias da humanidade, os filósofos propõem-se a ensinar ou reeducar o público a pensar através da literatura - como podemos ver em Jacques le fataliste et son maître de Diderot - mas sobretudo através do teatro, uma arte de tal forma difundida, na época, que será lícito classificar este século como o da teatromania.

É o fim da menoridade do homem, visto como um ser que devia ser conduzido por alguém exterior a si - Deus, Rei ou Senhor feudal - que não lhe era permitido questionar (nem como nem por que). Mandavam-no obedecer, não raciocinar. Até aí, essa faculdade não era reconhecida. Tinha pois de acreditar sem discutir, aceitar culpabilizando-se. O homem estava condenado desde o nascimento a uma escravidão física e moral.

Tirando o seu epíteto da religião - para a qual a luz é a verdade revelada - este século escolhe a designação das Luz̧es por oposição às trevas (do passado). Deste modo, a metáfora disfórica até então existente dá lugar a uma outra - desta vez eufórica assinalando a mudança de atitude do Homem, que resulta de uma nova visão do mundo.

O que muda é a atitude que passa de passiva a ativa. A atividade em questão decorre da predisposição para raciocinar, que é própria daquele que aceita o desafio que este século lhe lança através dos seus filósofos: sapere aude ("ousa saber"), ou seja, "aceita a mudança desconhecida que o saber, enquanto processo iniciático, te oferecerá”. No conceito de Luz̧es podemos incluir tudo aquilo que é suscetível de nos conduzir a um universo aberto

\footnotetext{
${ }^{2}$ Cf. a este propósito: SILVA, Maria de Fátima Sousa e. Crítica do Teatro na Comédia Antiga. Col. "Textos Universitários de Ciências Sociais e Humanas", Fundação Calouste Gulbenkian e Junta Nacional de Investigação Científica e Tecnológica”, 1987.
} 
que em si mesmo - enquanto razão, tolerância, progresso, liberdade, felicidade - funciona como fim e como meio. Porque se impõe compreender o mundo, este é visto através de um sistema de conceitos. E a sua compreensão está ao alcance de todos. Desta forma, o conhecimento (em vez de revelado) mais não é do que um conjunto sistematizado de conhecimentos humanos que os filósofos propõem ao público na obra ENCYCLOPÉDIE ou DICTIONNAIRE RAISONNÉ DES SCIENCES, DES ARTS ET DES MÉTIERS.

A língua é já vista como uma expressão cultural, o que significa que querer conhecer os seus princípios é querer conhecer o povo que a fala. Estamos aqui perante o início da formulação do princípio da Tolerância, a que Voltaire se dedicará. Assiste-se assim à constituição de um saber novo que se definirá, no final do século, como Anthropologie on science générale de l'homme (Alexandre Chavannes, 1788).

Os enciclopedistas estão conscientes da evolução universal, expressa por Diderot em Le Rêve de D'Alembert (1769):

Desde que vi a matéria inerte passar ao estado sensível, já nada me deve espantar. E que comparação poderá haver entre um pequeno número de partículas em fermentação na palma da minha mão e esse imenso reservatório de elementos múltiplos espalhados pelas entranhas da terra, pela superfície dos mares, pelo vácuo no seio do ar!

O comércio e a consequente mudança da estrutura social estão na origem do iluminismo, da nova mentalidade. Toda a mudança pressupõe um confronto de ideias, um diálogo, uma bilateralidade. É preciso questionar primeiro para em seguida mudar. O pôr em questão implica um jogo de espelhos que só é possível com a introdução do Outro, figura que se opõe ao Eu. Para que eu possa criticar-me tenho de me distanciar de mim mesma/o. Essa distância é conferida pela maturidade que me permite sair de mim para poder observar-me. Este século gerou as condições necessárias para que o Homem pudesse ver refletida a sua imagem e adotar uma atitude crítica.

É assim que podemos falar de leitura no sentido de uma construção feita pelo autor e pelo leitor (explícito ou implícito). Com a nova classe social - a burguesia - surgem novos interesses, novos valores, novos modelos, que entram em diálogo com os antigos, com o status quo. Se, na Idade Média, só o clero tinha acesso à leitura e à escrita, até aqui só a nobreza foi acrescentada. ${ }^{3}$ Sendo os interesses e os valores os mesmos, não há diálogo, pois o Outro é inexistente. No século XVIII, com o relevo social adquirido pela classe ascendente, desaparece o processo unilateral de leitura. A dialética autor / leitor torna-se possível porque há diferentes interesses em jogo.

\footnotetext{
${ }^{3}$ Sobre este ponto, aconselha-se a obra de Sartre “Qu'est-ce que la littérature?”.
} 
Todos aprendem e todos ensinam, e cada uma destas duas ações compreende a outra. O diálogo e o respeito pelo Outro tornam-nos disponíveis para aprender, logo, para evoluir.

Na sua obra crítica Lire les Lumières, Jean Jacques Tatin-Gourier afirma:

O filósofo do século XVIII passa pelo crivo os saberes transmitidos e aponta aos seus leitores as crenças infundadas e os sempre recorrentes riscos de erro. Não somente distingue a verdade da sua falsificação como isola e, a prazo, reduz as fontes de erro. O exame crítico dos costumes e das instituições deve permitir identificar as forças interessadas na corrupção dos espíritos. Por último, incita o leitor à análise crítica, à expressão de juízos de valor, condenações ou preferências. Os abusos e os preconceitos continuam a ser condenáveis em nome da Razão e da Natureza. (TATIN-GOURIER, 1996, p. 18)

E ainda: "A pedagogia, entendida em sentido lato, é uma das maiores preocupações dos filósofos". (Idem, p. 22)

É neste sentido que deve ser lido Jacques le fataliste et son maître, de Diderot, onde claramente se cumprem dois dos objetivos da filosofia das Luzes: denunciar os erros que impedem o progresso e formar uma opinião esclarecida.

Quando Diderot introduz a figura do leitor como personagem da sua obra, atribui um papel diegético à presença sem corpo desse leitor no momento da escrita. Dito isto, está já a jogar com a recepção. $\mathrm{O}$ autor tem consciência de não estar só no momento em que cria - está em diálogo permanente com o leitor, procurando corresponder as suas expectativas ou tentando ludibriá-lo.

A ironia a que o autor tão frequentemente recorre ao longo do texto faz do leitor um cúmplice ativo, tendo em vista a sua libertação de dogmas e interditos. Diderot oferece assim o seu contributo para a "educação nacional”, uma vez que podemos ver na sua obra, em sentido lato, uma reflexão pedagógica e, em sentido estrito, a educação do leitor - ou do público - no sentido de dele fazer "pessoas honestas que pensam", educando assim "essa populaça que de modo nenhum foi feita para pensar". Adotam-se aqui as definições de público formuladas por Voltaire em Questions sur l'Encyclopédie (1770, “Blé”).

O diálogo é, por excelência, a matéria do teatro. A sociedade e o teatro interagem e mudam em simultâneo. Ambos se tornam espaços de reflexão e discussão. Princípios que não podem ser negados - como a tolerância que está na base da igualdade defendida pela Revolução Francesa - são postos em discussão na cena teatral, não só por Voltaire como por Marie-Joseph Chénier, que faz apelo aos espectadores para deslindar o impasse gerado pelo confronto entre o patriotismo e a tolerância na sua primeira Azémire, em 1787.

A personagem feminina desta peça, Azémire, descendente da realeza e oriunda de um país oriental em guerra com a França, apaixona-se por um francês, também ele de 
origem real e seu inimigo. Está assim criado o dilema entre os valores nacionais e os valores do coração, defendidos por Pascal.

A personagem Turenne surge-nos dividida entre o apelo do coração e o apelo da razão, entre um amor tolerante ao ponto de fazer tábua rasa das diferenças religiosas e políticas e a razão que lhe fala de princípios como o patriotismo ou o nacionalismo.

A dialética instala-se e, com ela, a argumentação com os seus jogos retóricos, em que a figura da veemência (tanto do discurso dramático como do discurso jurídico) se manifesta na fala de D’Amboise, o embaixador, visando convencer a personagem que está prestes a esquecer a sua lealdade e o seu patriotismo por razões amorosas (quinto e último ato). Ainda que a pátria tenha saído vitoriosa, a discussão instalou-se e o público não gostou nada da peça.

Por motivos que se prendiam com a previsibilidade do desfecho e o imobilismo da ação, fruto da atitude de personagens amorfas, a crítica literária rejeitou a peça com que o seu autor se estreara na carreira dramatúrgica.

$\mathrm{Na}$ sala de teatro, os espectadores exprimiram o seu desagrado com assobios, devido à inércia da ação ou talvez ao conflito que se gerara no seu espírito, ou a ambos.

Marie-Joseph Chénier prometeu reescrever a peça quando o público tivesse aceitado uma das suas obras. Esse momento aconteceu quando o público reclamou a representação da sua peça Charles IX e esta se revelou um sucesso.

$\mathrm{Na}$ Lettre à $M$. le Chevalier de Pange, que serve de introdução à tragédia Azémire, publicada por Moutard, em 1787, Marie-Joseph Chénier queixa-se da intolerância dos seus contemporâneos, que tinham vaiado a peça do princípio ao fim logo na sua primeira representação em Fontainebleau, a despeito da juventude do seu autor, que estava ainda em início de carreira. Escreve ele:

[Eu] tinha na altura vinte e um anos e, como se deve incentivar os jovens, a minha Peça foi assobiada do princípio ao fim. Nunca, disseram-me, se vira semelhante coisa em Fontainebleau. O papel de D'Amboise foi o mais assobiado de todos. As vaias foram muito longas, sobretudo quando se chegou a estes versos:

Que dirão os franceses, que dirá o teu velho pai

Quando souber, etc.

Algumas pessoas, e mesmo alguns pretensos Letrados, tinham ouvido:

Que dirá Deus pai

[...] Em tudo aquilo, no entanto, duas coisas me espantavam: o Ator que desempenhou admiravelmente o papel de d'Amboise junta ao mérito tão raro de ser sempre enérgico e nobre o mérito de falar com enorme clareza (CHÉRNIER, 1787, pp. 69-70).

O texto é incompreendido e mal aceito. O público tem outras expectativas em relação ao tema e o texto revela-se ambíguo do ponto de vista fonético. 
O público e a crítica literária foram muito severos para com a peça, apontando a falta de ritmo da ação e a previsibilidade do desfecho. Para corrigir esses aspectos seria preciso pensar em reescrevê-la, já que o problema envolvia a obra inteira.

Apesar da intolerância dos espectadores, o autor, de carácter corajoso, propõe-se empreender essa tarefa depois de o público acolher bem outras das suas peças. É o que diz no final da sua carta (ou da sua queixa), que termina com o desafio lançado a si mesmo de reformular a peça, ainda que relegando-o para mais tarde: “[não] antes de haver merecido, se conseguir, a atenção do Público através de outras Obras (Idem, p. 72)"

A reescrita far-se-á num tempo indeterminado porque dependente de uma condição. A tolerância do autor manifesta-se no seu desejo de evoluir, aceitando as críticas como um meio de mudar.

Azémire manuscrita representará essa resposta? Podemos tentar seguir essa pista, verificando a sua validade no que respeita às alterações previstas na Lettre à $M$. Le Chevalier de Pange.

Passemos pois a uma breve análise das duas peças que apresentam o mesmo título, Azémire, uma impressa, a outra manuscrita e inédita.

Comecemos pela primeira, assinada e datada.

No que se refere à intriga, esta gira em torno do amor entre uma infiel, Azémire, Rainha do Sudão, e um cristão, Turenne, nobre francês, na época da Primeira Cruzada. Este conflito, externo e interno, constitui pois o tema de Azémire, já que o dilema moral atormenta o apaixonado Turenne, que acaba por escolher o amor à Pátria, que é também o da honra. D'Amboise, o embaixador, não é alheio a esta decisão, pois que é ele quem faz o derradeiro esforço, bem sucedido, aliás, para reconduzir Turenne “à razão e à França”.

A França e a Inglaterra combatem lado a lado nesta guerra expansionista em que o Ocidente invade o Oriente. Ambas são referidas como "essa Europa insolente" ou "a Cruz insolente" que invade "a Ásia agonizante" (Idem, p. 86).

Para materializar a situação de guerra vivida, a ação situa-se nas muralhas. Podemos ler logo no início: "Estas muralhas, estes caminhos eriçados de armas".

A intriga coloca em primeiro plano o dilema moral decorrente da possibilidade / impossibilidade de união entre uma jovem rainha do Sudão, e Turenne, o inimigo cristão por quem ela sente um grande amor. Este reage à ideia de dever defender a sua amada, exprimindo desta forma o seu conflito:

Eu! Contra Cristãos! Não tenhais tal pretensão Eu! Que de todos os meus execrável homicida Vá pelas vossas muralhas procurar o parricida? 
$[\ldots]$

Considerai que o meu ódio não é devido aos Cristãos

E não mais ordeneis aos meus sentidos enternecidos

De ir agora assassinar todos os que me são queridos (Idem, p. 89).

Estamos perante uma ação simples, característica que Marie-Joseph Chénier energicamente defende, enquadrando-a na austeridade das Obras clássicas. $\mathrm{Na}$ sua Lettre à M. Le Chevalier de Pange escreve, refutando as críticas que lhe foram dirigidas: "Aristóteles, esse grande admirador da Tragédia, que coloca até acima da Epopeia, esse crítico Filósofo que tão profundamente refletiu sobre a natureza das Artes, Aristóteles recomenda expressamente a simplicidade da ação trágica.” (Idem, Tomo I, p. 68)

Todavia, a crítica da época não partilha a sua opinião e, falando ainda da ação, censura-lhe a previsibilidade do desfecho, ao qual nada se contrapõe. De facto, não encontramos nela qualquer peripécia, a não ser no plano psicológico e muito débil. É preciso ver que a reflexão de Turenne é suscitada pelas palavras de Azémire, que reage à intenção manifestada por Soliman de a vingar, numa sequência muito natural e numa atmosfera doce e cândida: "SOLIMAN [...] Os vossos discursos menos cruéis deveriam ter aplacado. / Um Sudão que vos ama e que pode vingar-se” (Idem, p. 87)

Esta cena passa-se no final do primeiro Acto.

O segundo começa justamente com a reacção de Azémire à ideia de ser defendida por Soliman em vez de Turenne, que ela ama: “AZÉMIRE: [...] Ele sabe que doravante já nada tenho a temer./Que um outro soube agradar-me, e que um outro nos combates[...]" (Idem, p. 89).

Aqui começa a reflexão de Turenne, confrontado com a ideia de dever defender a sua bem-amada, a sua rainha, contra os Cristãos, contra os seus amigos e a sua família. D’Amboise, o embaixador, limita-se a dar continuidade a esta reflexão, suscitando-a.

Ainda que a decisão de Turenne seja enunciada logo no final do primeiro Ato, e mesmo que Azémire possa tê-la interpretado como indecisão, ela é categoricamente tomada e anunciada na cena 7 do quarto Acto.

\section{TURENNE}

Viver a adorar-vos era o meu doce forte Mas cumpre-me morrer e morrerei longe de vós Reinai, esquecei-me. É a vós que afianço, Vós, minha Religião, uma glória funesta; Amo-vos; e corro a cumprir uma ordem do Céu Ficar é-me impossível (Idem, p. 127). 
Depois de ter ouvido a decisão de Turenne, o Francês por quem está apaixonada, Azémire toma também a sua decisão, que é a de morrer:

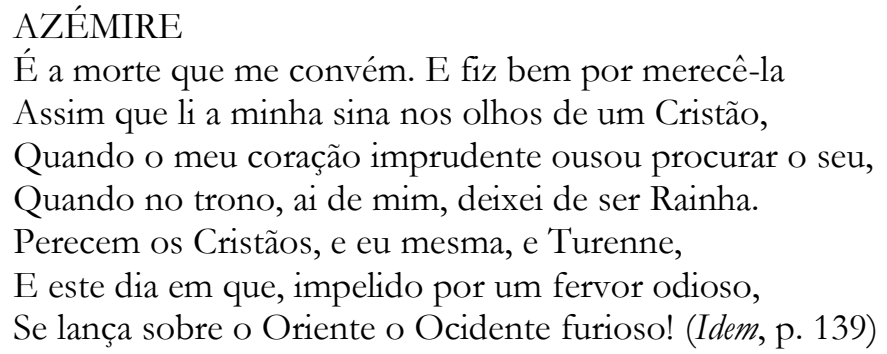

A peça termina com Azémire a soltar o último suspiro no final do quinto Ato. Marie-Joseph Chénier manteve-se fiel ao número de atos prescrito por Horácio.

Este aspecto do desenlace previsível é comentado por um escritor periodista, autor de L'Année Littéraire.

O dramaturgo, de vinte e um anos, manifesta a sua discordância recorrendo uma vez mais aos clássicos:

Uma das críticas que ele faz à Peça é que o desenlace já era de prever. Há, porém, tragédias em que o próprio título anuncia o desfecho, como é o caso da morte de César. Mas há mais: o desenlace está necessariamente previsto em todas as Tragédias baseadas na História. (Idem, p. 71)

Ousaríamos dizer que a ação se desenrola de uma forma tão natural e expectável que se torna impossível sentir terror ou piedade, mesmo considerando a distância de mais de dois séculos. Mas, sobre este ponto, Chénier recorre de novo a Aristóteles, dizendo:

O mesmo Crítico exige que o terror e a piedade sejam excitados pelo próprio fundo do drama, e não pelo espetáculo. Ele pretende que se possa chorar ou estremecer fechando os olhos, unicamente escutando a Tragédia - o que só pode acontecer pela veracidade das situações e pela eloquência do estilo (Idem, pp. 68-9).

É verdade que, na tragédia, o discurso sustenta a ação e informa sobre o que se passa. Diríamos mesmo que o faz excessivamente, pois tem-se a impressão de que a ação é sobretudo interior, que se desenrola na intimidade dos sentimentos e do pensamento das personagens. O espectador toma conhecimento do que se passa com as personagens através dos seus monólogos e diálogos, mas o ritmo da peça sofre forçosamente os efeitos dessa ação psicológica.

Sente-se a tal ponto a falta de acção exterior que uma das críticas feitas gira em torno da inércia de Soliman, o rei com quem Azémire se deveria ter casado.

O autor aceita igualmente essa crítica, mas não sem tentar justificar o papel desta personagem, recorrendo uma vez mais aos clássicos. E escreve: 
Uma outra crítica que se faz à Tragédia de Azémire é a inação de Soliman. Esta censura parece-me inteiramente justificada. Creio que esse é, de fato, o principal defeito da Peça, e que esta falha torna por vezes o curso da história entediante. [...] Mas, atendendo à composição da personagem, parecia-me impossível mudar o papel de Soliman. Confesso que já não estou tão convencido disso. Essa mudança, porém, que tornaria o andamento da Peça mais vivo e mais intensamente trágico, exigiria um trabalho considerável que eu não tenho o direito de empreender antes de haver merecido, se conseguir, a atenção do Público através de outras Obras. (Idem, p. 72)

Marie-Joseph Chénier faz do fracasso da sua tragédia uma aprendizagem, propondo-se mesmo reescrevê-la, embora não de imediato. $O$ autor faz toda uma reflexão sobre os motivos do desastre e as críticas de que foi alvo, a fim de tomar consciência do que seria necessário mudar para que a sua tragédia fosse um sucesso.

Não o faz, porém, de forma passiva: argumenta, recorrendo aos exemplos das Tragédias clássicas, nomeadamente a Aristóteles, "esse grande admirador da Tragédia, [...], esse crítico Filósofo que tão profundamente reflectiu sobre a natureza das Artes”, e também a Voltaire.

É preciso dizer que a intenção do jovem dramaturgo não é obedecer cegamente a quem quer que seja, nem mesmo a Aristóteles ou a Voltaire.

A propósito deste último filósofo, podemos acrescentar que o conteúdo das duas peças (Azémire impressa e Azémire manuscrita) contraria a visão de Voltaire, expressa nas suas Lettres Philosophiques, uma vez que a riqueza proveniente do comércio não conferiu ao povo inglês a superioridade de um modelo a seguir - fazendo referência à peça impressa após a representação desastrosa - nem tão pouco o progresso e a liberdade, mas antes a barbárie, segundo os termos utilizados na obra manuscrita.

Os costumes, a intriga e o tema fazem parte de uma mesma preocupação do autor, a da simplicidade que ele encontra nos clássicos.

Obedecendo a esta preocupação de simplicidade, podemos facilmente observar que há nas duas peças uma ação única, que gira em torno da guerra entre o Ocidente e o Oriente e do dilema moral que daí se gera.

Na peça manuscrita, Azémire, designada pelo seu marido como "A augusta metade do monarca da Índia", encontra-se dividida entre o amor que sente pelo marido e o amor pelo pai. Este conflito interior é exprimido por ela, no início do quinto Ato, de uma forma muito intensa e até mesmo violenta:

Nutro, contra minha vontade, desejos parricidas...

Julgo ouvir dos combatentes os gritos infernais...

Julgo ouvir meu esposo na sua hora derradeira,

Crivado de golpes, morrendo, injuriado pelo meu pai... 
Pelo meu pai! E todavia estremeço pela sua vida! ${ }^{4}$

Será, talvez, a solução encontrada para o difícil problema colocado na peça impressa. Como resolver a questão da tolerância e da legitimidade do amor entre dois seres pertencentes, cada um deles, a um dos exércitos adversários em guerra? Como compreender a situação criada - traição, covardia, ou tolerância, amor legítimo?

Pondo o pai no lugar do marido, a situação torna-se mais cômoda e mais fácil de resolver. Mais ainda se reconhecermos a traição do pai de Azémire que consegue fazê-lo compreender, perdoando-lhe e perdoando-se, após todo um percurso semeado de estratégias frementes em sentido contrário.

Dir-se-ia que o autor dedicou uma particular atenção a este aspecto da ação - as peripécias e o desenlace - que tão atacado fora aquando da representação da primeira peça.

Regressando à segunda peça, uma vez que o seu pai, Thomas, Rei da Pérsia, fizera uma "pérfida aliança" (Cena 1, Quarto Ato) com os ingleses, Azémire propõe-lhe que renove uma "Santa Aliança" com o seu marido.

O povo inglês é visto por Azémire como bárbaro (p. 49, Cena 4, Quarto Ato), como perigoso (Cena 3, Terceiro Ato), e Hyder, seu marido e príncipe, que se opõe aos ingleses, fala deles contrastando-os com o povo francês.

Fala-se então do povo francês. Mas em que termos é ele referido? Nos termos de Voltaire, que, na sua carta X, Sobre o comércio (1734) se debruça sobre o progresso histórico gerado pelo desenvolvimento do comércio, sobre o qual fala e que o leva a comparar a França à Inglaterra, considerando "a França a imagem inversa da Inglaterra" e conferindo a esta última o estatuto de modelo? Sendo a razão apontada a riqueza proveniente do comércio, que torna o homem livre: "O comércio, que enriqueceu os cidadãos em Inglaterra, contribuiu para torná-los livres e essa liberdade permitiu, por seu turno, expandir o comércio. Assim se criou a grandeza do Estado"5.

Ao mesmo tempo, são inventariadas as vantagens decorrentes da liberdade religiosa, política e económica.

Sim e não.

Nos dois textos, a França e a Inglaterra aparecem em situação de guerra.

Ambos os textos contrariam a visão voltaireana expressa nas Lettres Philosophiques, que confere à Inglaterra o estatuto de modelo.

\footnotetext{
4 Tradução nossa da nossa transcrição do manuscrito.

${ }^{5}$ VOLTAIRE, Lettre X in Lettres philosophiques.
} 
Nas duas peças, o autor manifesta um enorme sentimento patriótico. Todavia, a questão da guerra está sempre presente, tanto nas peças como nas reflexões acerca da sociedade, da história, da política. Questionam-se as motivações da guerra e a tolerância, a razão e a verdade.

Podemos afirmar que, para Chénier, estão em jogo os princípios e valores que formam um ser superior, pelos quais lutará toda a sua vida e de onde extrairá a sua força. Na sua obra, e em particular nestas duas peças, é a mulher, ser sensível por definição, que detém a superioridade, fazendo prova de compreensão e, nessa medida, de tolerância. Para ela, nada existe para além do amor, invencível e indiferente a barreiras políticas e / ou religiosas. Este símbolo de tolerância escuta unicamente a voz do seu coração.

Na peça representada, e uma vez que Azémire é vanguardista, no que diz respeito à mentalidade do seu tempo que demonstra uma incapacidade de tolerância ou de respeito pelo Outro, o que redunda no mesmo, a saída apresentada é a Morte, o destino do mártir. Tornam-na mártir da intolerância social e política. Os limites da tolerância prendem-se com o estádio de evolução dos seus contemporâneos.

Decorridos mais de dois séculos, dir-se-ia que houve tempo de sobra para cumprir a tolerância e desfazer a separação Eu/Outro que mais não é do que a separação da Vida. O Teatro deve assumir o seu papel de vanguarda nesta tomada de consciência da Unidade. Se Corneille já soube ultrapassar a obrigatoriedade do final funesto. Se o século das Luzes fez do Homem o agente do seu próprio destino. Então que o século XXI dê o passo decisivo de acabar com o padrão do sofrimento humano e traga à luz o Homem uno com a Vida, com a Fonte. Cabe à Arte ajudar à tomada de consciência da verdadeira identidade do Ser humano que está para além de qualquer credo, raça, religião ou opinião e que se funde na Unidade. O palco - enquanto projeção antecipada - deve demonstrar a responsabilidade de cada um pelo sofrimento que tem assolado a humanidade. Se cada indivíduo se responsabilizar por si próprio e pelo seu estado de espírito, a mente coletiva poderá limparse do padrão de sofrimento que tem vindo a estigmatizar a humanidade. Inicialmente, a tragédia mostrava o sofrimento como um castigo divino, ligado à providentia, e inerente à natureza humana. A partir do século XVIII, a ação dramática ligou-o à condição humana. Adotemos agora o padrão mental do Homem Feliz, com todas as capacidades para criar também a felicidade. 


\title{
REFERENCIAS BIBLIOGRAFICAS:
}

CHÉNIER, M. J. CEuvres [document électronique], de l'imprimerie de Firmin Didot, revues, corrigées et mises en ordre par D. CH. Robert, Guillaume, libraire, 1787.

FORESTIER, Georges. Situation de la tragédie classique. In: CORVIN, Michel. Dictionnaire encyclopédique du théâtre. Bordas, 1991.

PEREIRA, Miguel Baptista. Iluminismo e Secularização. In: O Marquês de Pombal e o seu tempo. No especial da Revista de História das Ideias. Faculdade de Letras da Universidade de Coimbra, 1982.

SOUSA E SILVA, Maria de Fátima. Crítica do teatro na comédia antiga. Col. Textos universitários de Ciências Sociais e Humanas. Fundação Calouste Gulbenkian e Junta Nacional de Investigação Científica e Tecnológica, 1987.

TATIN-GOURIER, Jean Jacques. Lire les Lumières. Paris, Dunod, 1996.

\begin{abstract}
The Enlightenment explores the path of rhetoric debate in the philosophical domain, as well as in the literary and theatrical, where the latter is the voice of the former. Society and the theatre interact and change simultaneously. Principles that are not subject to denegation, such as tolerance, which is at the very basis of the equality upheld by the French Revolution, are questioned on stage by Voltaire, as well as by Marie-Joseph Chénier.
\end{abstract}

Keywords: Enlightenment; tolerance. 